\title{
A Rare Case of Serrated Polyposis Syndrome with the MSH6 and SMARCA4 variants
}

\author{
Mahesh Nepal ${ }^{1}$, Sravani Lokineni ${ }^{1}$, Le Yu Naing ${ }^{1}$, Jay Bapaye ${ }^{1}$, Erik Olson ${ }^{2}$ \\ ${ }^{1}$ Department of Internal Medicine, Rochester General Hospital, Rochester, New York, USA \\ 2Department of Gastroenterology, Rochester General Hospital, Rochester, New York, USA
}

Received: 17/06/2021

Accepted: 21/06/2021

Published: 29/07/2021

\begin{abstract}
How to cite this article: Nepal M, Lokineni S, Naing LY, Bapaye J, Olson E. A rare case of serrated polyposis syndrome with the MSH6 and SMARCA4
\end{abstract} variants. EJCRIM 2021;8: doi:10.12890/2021_002750.

Conflicts of Interests: The authors declare there are no competing interests.

This article is licensed under a Commons Attribution Non-Commercial 4.0 License

\section{ABSTRACT}

Serrated polyposis syndrome (SPS) is the most common form of polyposis syndrome and has been shown to increase the risk of colorectal cancer (CRC). The genetic pathway of CRC in SPS is different from the classic adenomatous polyposis coli (APC) pathway, which accounts for $70-80 \%$ of cases of CRC. Most commonly, SPS mutations include BRAF and KRAS, with activation of the RAS-RAF-MAP kinase pathway involved in the pathogenesis of serrated lesions. We present a rare case of SPS in a 32-year-old woman with MSH6 and SMARCA4 variants, which have not previously been reported in the literature.

\section{LEARNING POINTS}

- Patients with serrated polyposis syndrome should receive frequent colon cancer screening.

- Patients and their relatives should undergo surveillance.

\section{KEYWORDS}

Serrated polyposis syndrome, colonoscopy

\section{CASE DESCRIPTION}

A 32-year-old woman presented to the emergency department with a 3-day history of abdominal pain. She also had bright red blood per rectum for 1 day with a history of long-standing constipation. Physical examination was unremarkable. The patient was managed symptomatically for constipation in the hospital. She underwent an outpatient colonoscopy and was found to have two $10 \mathrm{~mm}$ flat ascending colon polyps (Fig. 1) and one $1.5 \mathrm{~cm}$ flat polyp in the cecum, which were removed with saline lift. Pathology revealed sessile serrated adenoma. Six months later, another screening colonoscopy showed two $4 \mathrm{~mm}$ sessile polyps and two $1 \mathrm{~cm}$ flat polyps in the ascending colon, and one 7 $\mathrm{mm}$ flat polyp in the transverse colon, which were removed with a cold snare. Pathology showed that two were serrated adenoma, and the rest were tubular adenoma.

After continued surveillance with colonoscopy and treatment with polyethylene glycol and linaclotide, bowel movements have been regular, but the patient has episodes of intermittent rectal bleeding and abdominal pain. She was referred to genetic counselling and underwent genetic testing. Thirty-six genes associated with colorectal cancer (CRC) were analysed and revealed the patient was heterozygous for the variants MSH6 p.E641K and SMARCA4 p.V750F. The patient has been scheduled for surveillance colonoscopy 1 year after the previous procedure. 


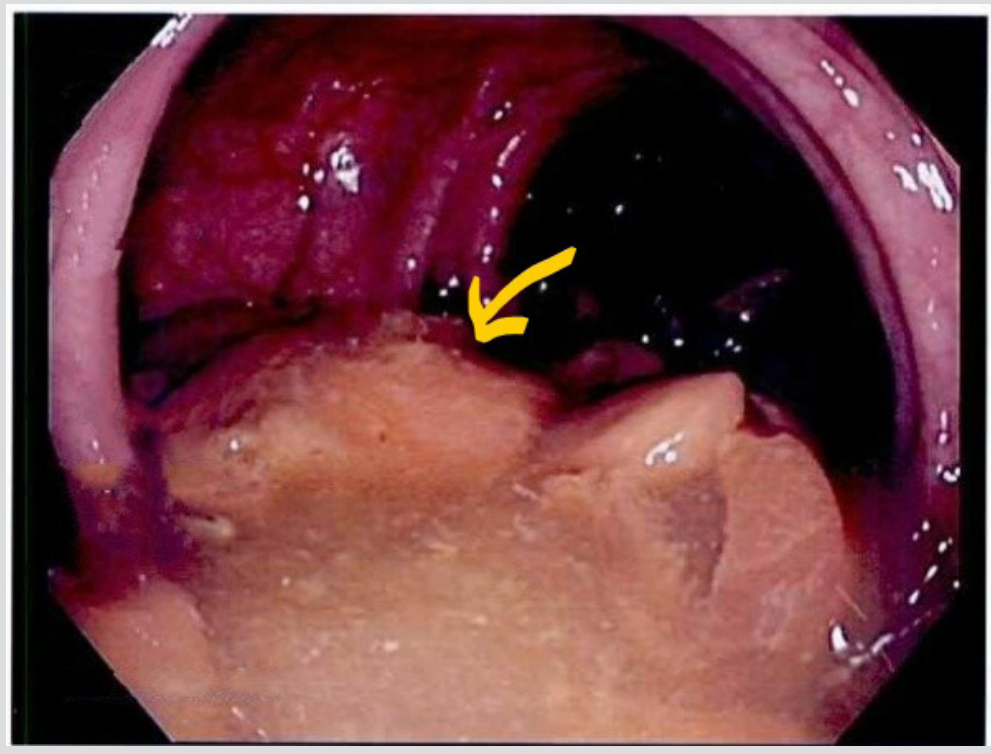

Figure 1. The chest $x$-ray was remarkable for extensive pneumomediastinum and subcutaneous emphysema in the chest, neck and shoulders

\section{DISCUSSION}

The most common polyposis syndrome is serrated polyposis syndrome (SPS) characterized by numerous serrated colorectal polyps often with no symptoms but also with occasional bleeding per rectum, abdominal pain, diarrhoea and constipation ${ }^{[1]}$. The diagnosis is made according to the criteria of the World Health Organization: (1) At least five serrated polyps proximal to the sigmoid colon, with two or more being $10 \mathrm{~mm}$ or more in diameter; (2) Any number of serrated polyps proximal to the sigmoid colon in an individual with a first-degree relative with SPS; and (3) 20 or more serrated polyps of any size distributed throughout the colon ${ }^{[1]}$. The incidence of advanced neoplasia was higher in criterion 1 SPS rather than in criterion 3 SPS ${ }^{[2]}$. The cumulative risk for CRC was $1.3 \%$ over 5 years of follow-up. The cumulative risk of CRC was doubled (53\% vs $26 \%$ ) when there were two or more polyps $1 \mathrm{~cm}$ or more in size, compared with having 20 or more smaller polyps $^{[2]}$.

Surveillance colonoscopy every 1-2 years to remove polyps in patients with SPS is recommended.

During the study period of 5 years, the cumulative incidence of advanced neoplasia was $24 \%$ in patients undergoing 1 -year interval colonoscopy compared with $16 \%$ undergoing 2 -year interval colonoscopy ${ }^{[2]}$. SPS incidence in the first-degree relative of patients with SPS is $32 \%{ }^{[3,4]}$. In first-degree relatives of patients with SPS, screening colonoscopy is recommended at 40 years of age or 10 years earlier than the age of SPS diagnosis in the index patient, and should be repeated every 5 years ${ }^{[4-6]}$.

The genetic abnormalities associated with SPS can be classified into two groups: those associated with the BRAF mutations which are predominantly right-sided polyps and those associated with the KRAS mutations, which are predominantly left-sided polyps ${ }^{[1]}$. Other abnormalities reported in the literature are methylation in P16, MINT1, MINT 31 and MLH1. These latter genes are associated with an up to 14-fold increased risk of having familial SPS. PTEN mutations and MYH mutations are other reported abnormalities in SPS [1,6].

We report a case of SPS where genetic studies showed variants in the MSH and SMARCA4 genes, the significance of which for pathogenesis or genetic risk to the patient is still unknown. There were no abnormalities in the common genes, like BRAF and KRAS, which account for almost $75 \%$ of SPS cases.

\section{CONCLUSION}

The list of genetic abnormalities implicated in SPS has been growing with the extremely heterogeneous nature of the disease. The individual risk associated with the different genotypes is of interest for future study. 


\section{REFERENCES}

1. Guarinos C, Sánchez-Fortún C, Rodríguez-Soler M, Alenda C, Payá A, Jover R. Serrated polyposis syndrome: molecular, pathological and clinical aspects. World J Gastroenterol 2012;18(20):2452-2461.

2. Bleijenberg AG, IJspeert JEG, van Herwaarden YJ, Carballal S, Pellisé M, Jung G, et al. Personalised surveillance for serrated polyposis syndrome: results from a prospective 5-year international cohort study. Gut 2020;69(1):112-121.

3. Egoavil C, Juárez M, Guarinos C, Rodríguez-Soler M, Hernández-Illán E, Alenda C, et al. Increased risk of colorectal cancer in patients with multiple serrated polyps and their first-degree relatives. Gastroenterology 2017;153(1):106-112.e2.

4. Oquiñena S, Guerra A, Pueyo A, Eguaras J, Montes M, Razquin S, et al. Serrated polyposis: prospective study of first-degree relatives. Eur J Gastroenterol Hepatol 2013;25(1):2832. doi: 10.1097/MEG.0b013e3283598506. PMID: 23011040.

5. Balaguer F, Pellise M. Serrated polyposis-should we screen first-degree relatives? Nat Rev Gastroenterol Hepatol 2014;11(6):333-334.

6. Mankaney G, Rouphael C, Burke CA. Serrated polyposis syndrome. Clin Gastroenterol Hepatol 2020;18(4):777-779. 